Article

\title{
Assessing the Influences of a Flood Diversion Project on Mitigating River Stage, Inundation Extent and Economic Loss
}

\author{
Wei-Bo Chen ${ }^{1}$, Wen-Cheng Liu ${ }^{2,3, *}$, Huei-Shuin Fu ${ }^{1}$ and Jiun-Huei Jang ${ }^{1}$
}

1 National Science and Technology Center for Disaster Reduction, New Taipei City 23143, Taiwan; E-Mails: wbchen@livemail.tw (W.-B.C.); hsfu@ncdr.nat.gov.tw (H.-S.F.); jamesjang@ncdr.nat.gov.tw (J.-H.J.)

2 Department of Civil and Disaster Prevention Engineering, National United University, Miaoli 36063, Taiwan

3 Taiwan Typhoon and Flood Research Institute, National Applied Research Laboratories, Taipei 10093, Taiwan

* Author to whom correspondence should be addressed; E-Mail: wcliu@nuu.edu.tw; Tel.: +886-37-382-357; Fax: +886-37-382-367.

Academic Editor: Athanasios Loukas

Received: 5 February 2015 / Accepted: 13 April 2015 / Published: 22 April 2015

\begin{abstract}
Taiwan usually suffers severe inundation disasters during typhoons and strong rainstorms, and therefore flood mitigation is considered an important issue. To assess the effect of the Yuansantze flood diversion tunnel (YFDT) on flood mitigation at the upstream reaches of the Keelung River, a three-dimensional, unstructured grid, Finite-Volume, primitive equation Community Ocean Model (FVCOM) was used. The model was validated with observed data for water levels and inundation extent during different typhoon events. The simulated results show a good agreement with field measurements of water level with three historical typhoon events but underestimated the measured inundation extent with Typhoon Nari. The validated model was then applied to assess the flood mitigation and economic loss with the YFDT. The results demonstrated that the river level decreases approximately $3 \mathrm{~m}$ with the YFDT and that the inundation extent decreases by more than $50 \%$ in the Ruifang District with YFDT. The YDFT aims to not only mitigate hazards but also reduce economic losses. The average annual expected benefit after construction of the YFDT is approximately 184 million NTD in the Ruifang District.
\end{abstract}


Keywords: flood mitigation; Yuansantze flood diversion tunnel; unstructured grid; Keelung River; economic loss; FVCOM

\section{Introduction}

Flash floods and flooding pose severe hazards to human populations in many parts of the world. Floods produce a heavy toll on human life and property every year and are considered to be the most common, costly and deadly of all natural hazards. Floods present so many problems that no single measure can solve all of them. The basic principle included in all methods concerned with flood mitigation is to "Keep floodwaters away from man and man away from the floodwaters" [1]. Knowledge of floods is necessary to mitigate and reduce the damage they cause.

Taiwan is located at the intersection of the Euro-Asian continent and the Pacific Ocean, and it suffers from typhoons during both summer and fall. The annual rainfall is substantial, averaging $2500 \mathrm{~mm}$, of which almost $80 \%$ falls during the period from May to October as a result of the Mei-yu fronts and associated typhoon events. Over the past several years, Taiwan has experienced several severe flood disasters involving major river basins. One factor contributing to the severity of the disasters is the unexpected failure of levees and the resulting inundation of adjacent regions. Another factor is the overtopping of levees at upriver reaches because of extremely heavy rainfall during typhoon events [2]. Because of the urgent need to resolve flood problems, structural measures including high-level protection levees and pumping stations, diversion channels, and detention reservoirs serve as the main strategies and non-structural measures including flood warning systems, delimited retarding basins, disaster insurance, etc. are adopted as supplements to strengthen flood sustainability [3]. The Yuansantze Flood Diversion Works Project, one of the largest flood mitigation projects in Taiwan in the last decade, was built over the three years from 2001 to 2004, and it now positively influences approximately 6.5 million people in the Taipei metropolitan area. It has diverted $1.4 \times 10^{8} \mathrm{~m}^{3}$ of water in 27 flood events from 2004 to 2013 [4], and during this period, flooding has not occurred in the Taipei metropolitan area. Undoubtedly, the Yuansantze Flood Diversion Project has a significant contribution to the mitigation of inundation disasters and economic losses.

Numerous numerical models have been developed and applied to simulate the river stage and inundation extent caused by storm surge, heavy rainfall, and high river flow in the coast and river floodplain regions [5]. Several researchers [6-9] have reported their studies on inundation in the coastal and river floodplains, but few studies have presented the effects of flood diversion projects on mitigation of the river stage, inundation extent, and economic losses.

Although one-dimensional hydrodynamic models have been widely adopted in many studies, they cannot represent the actual meandering river shape and flow over the floodplain [10]. Two-dimensional model is undoubtedly more efficient in computational time than three-dimensional model. From the physical point of view, however, three-dimensional model can describe more reality of fluid than two-dimensional model. For instance, three-dimensional velocity field is more reliable compared to the depth-averaged velocity field. The main objective of this study is to construct a three-dimensional unstructured grid hydrodynamic model to simulate river stages and inundation patterns in the upstream 
reach of the Keelung River as well as to examine the capability of the Yuansantze Flood Diversion Project to mitigate flood disasters and economic losses. The high-resolution model was calibrated and verified with the observed water levels for three typhoon events and inundation extent of a typhoon event. The validated model was adopted to compute the inundation depth and extent induced by river flows for different return periods. Additionally, the average annual expected benefit after construction of the Yuansantze Flood Diversion Tunnel (YFDT) was estimated using the loss assessment system. The structure of this report is as follows. Section 2 provides a description of the study area. The methodology for model set up and data processing are presented in Section 3. Model validation is given in Section 4. Model assessments of the capabilities of the flood diversion project are described in Section 5. Finally, a summary of this study is provided in Section 6.

\section{Description of the Study Area}

The construction site of the flood diversion works at Yuansantze is located at the upper land catchment of the Keelung River (Figure 1). The Keelung River basin has a drainage area of $501 \mathrm{~km}^{2}$ with a mainstream length of $86 \mathrm{~km}$. The Keelung River is one of the three major tributaries of the Tamsui River in northern Taiwan, flowing through the Taipei metropolis. It is rather steep in the upstream and very flat in the lower downstream. This terrain is ideal for frequent flooding when heavy downpours occur in the river basin. Rapid urbanization resulted in the formation of highly developed and densely populated zones over the Keelung River basin. The hydraulic facilities that existed before the project was initiated were unable to provide secure flood protection. Based on its design, the YFDT can divert $1310 \mathrm{~m}^{3} / \mathrm{s}$ of water at the designed peak discharge from the upper Keelung River basin into the East China Sea (Figure 1), and the remaining design flood of $310 \mathrm{~m}^{3} / \mathrm{s}$ is discharged into downstream of river weir in the Keelung River [11]. The YFDT provides an assurance of flood-carrying capacity and significantly increases the safety of the Keelung River basin under 200-year return-period flood protection.
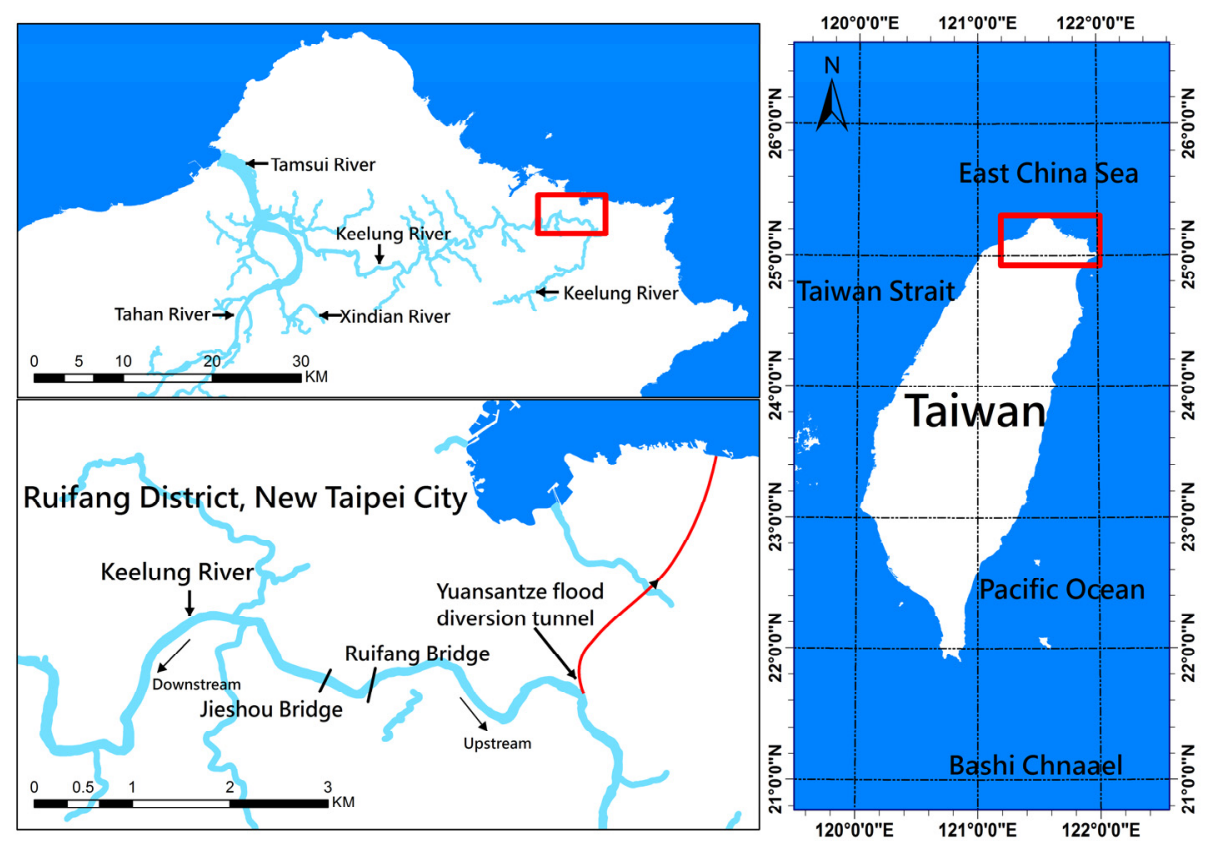

Figure 1. Map of the study area. (White, blue, and cyan represent land, ocean, and river, respectively). 


\section{Materials and Methods}

\subsection{Data}

The measured data used in this study can be categorized into two groups: one is the hydrological data used for calibrating the model parameters and verifying the model performance, and the other one is the geographical data used for the model set up.

The measured data used for model validation include time-series water levels and river flows as well as inundation extent. Water levels and river flow are gauged by the Water Resource Agency, Taiwan at the Yuansantze diversion weir (Figure 2c) every $10 \mathrm{~min}$.

A digital elevation model (DEM) with a resolution of $5 \mathrm{~m} \times 5 \mathrm{~m}$ and measured data for the cross-section in the river channel were collected from the Ministry of the Interior and the Water Resource Agency in Taiwan, respectively. Through these precisely measured data, the topography in the Keelung River and its surrounding can be accurately represented in the model.

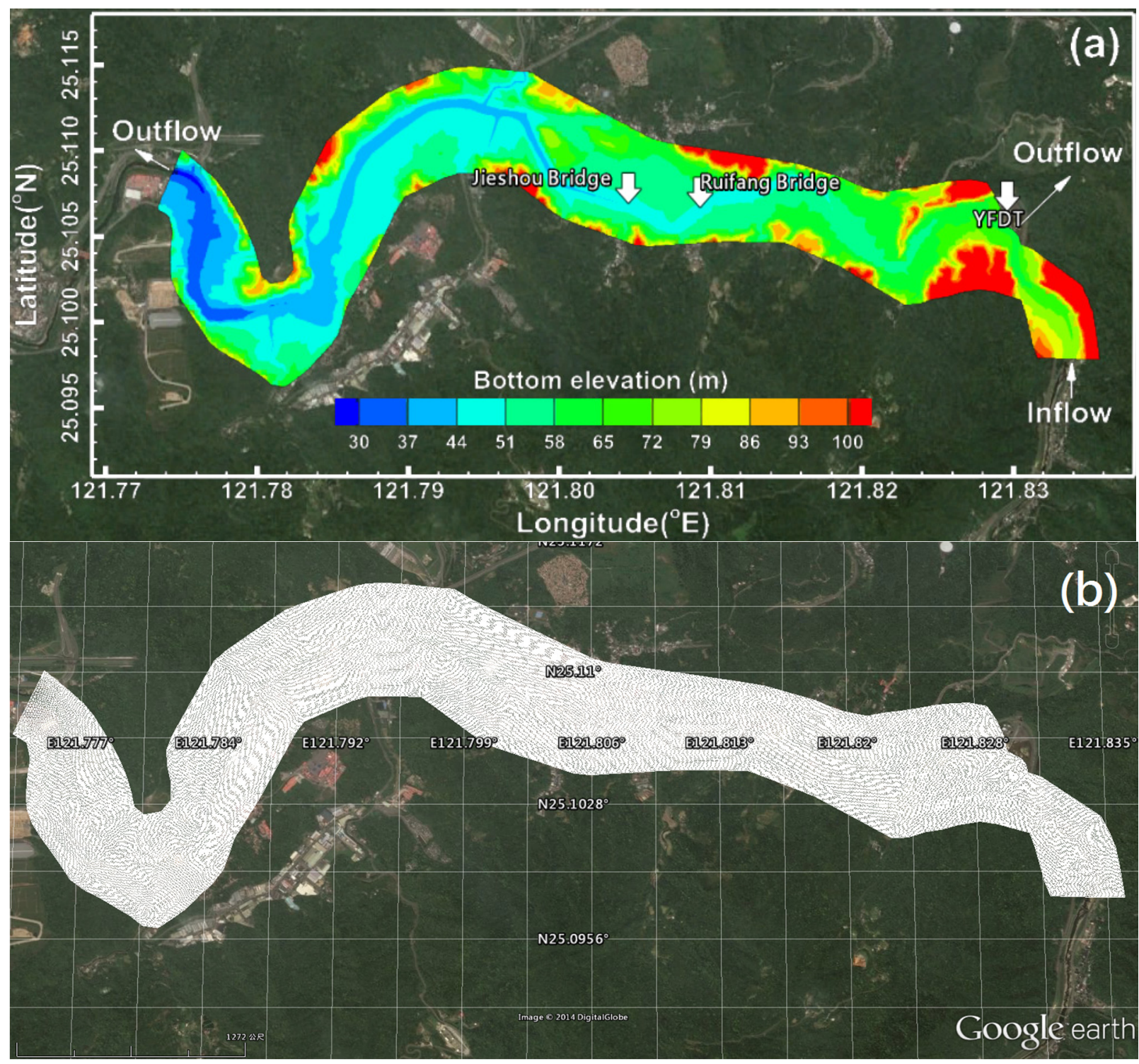

Figure 2. Cont. 


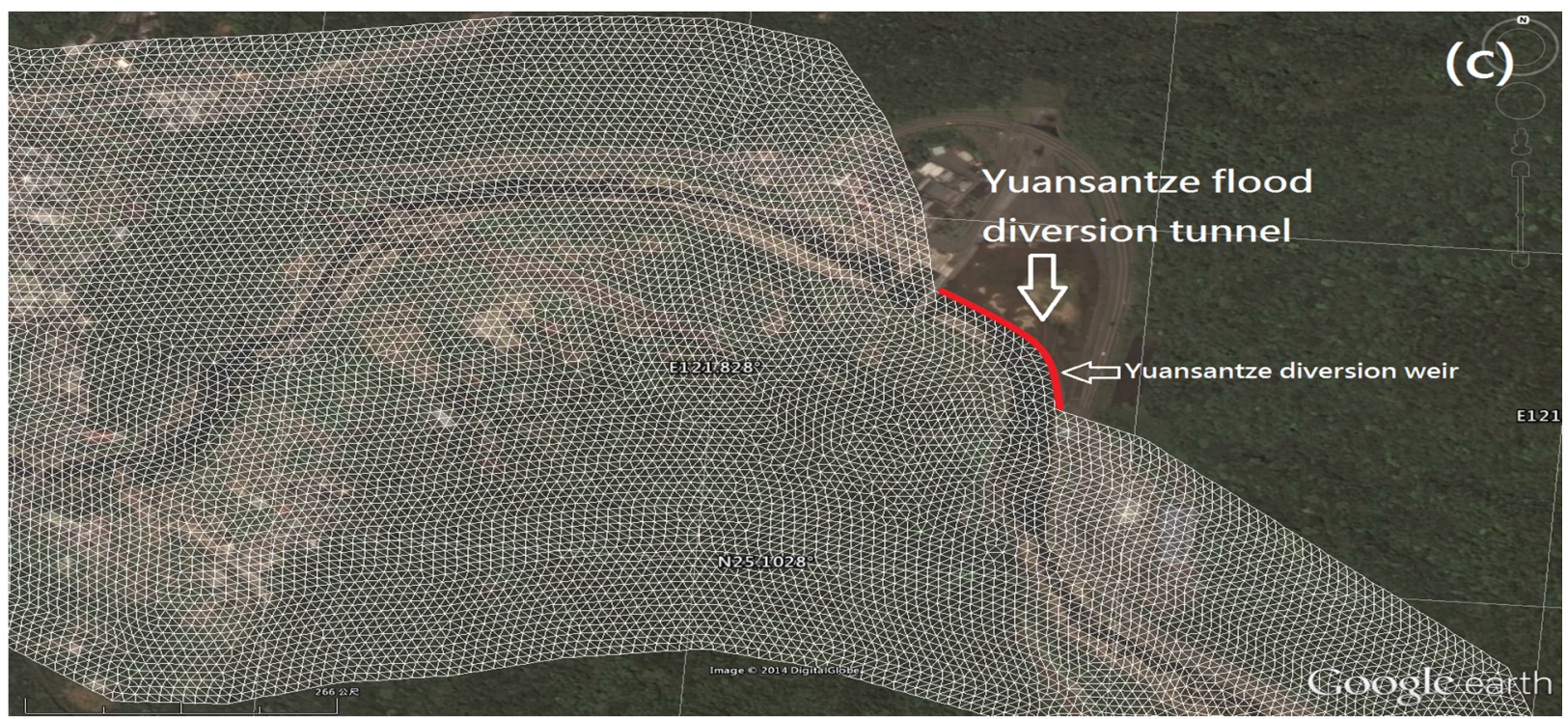

Figure 2. (a) Bathymetry and topography for the model domain; (b) unstructured grids for the model domain; and (c) high-resolution meshes at the Yuansantze flood diversion.

\subsection{Hydrodynamic Model}

In terms of accurately simulating the river stages and inundation phenomena around a river, two components, which are an unstructured-grid framework model and a model with the capability to address wetting and drying processes in areas surrounding the river, are important to highlight in this study. A three-dimensional, unstructured grid, finite-volume, primitive equation Community Ocean Model, FVCOM [12,13], was applied to calculate the river stages and inundation extents with and without the Yuansantze flood diversion tunnel of the Keelung River at the Ruifang District.

FVCOM adopts a finite-volume method to solve the three-dimensional shallow water equation for free surface elevation and water velocity. A triangular grid system and a generalized terrain following coordinate are used in the horizontal and the vertical directions. In this study, we used only the barotropic mode in FVCOM to simulate the water level and inundation extent. The barotropic mode of FVCOM consists of continuity and momentum equations based on the Boussinesq and hydrostatic approximation. The equations in the Cartesian frame of reference are given below:

$$
\begin{gathered}
\frac{\partial u}{\partial z}+\frac{\partial v}{\partial z}+\frac{\partial w}{\partial z}=0 \\
\frac{\partial \eta}{\partial t}+\frac{\partial}{\partial x} \int_{-h}^{\eta} u d z+\frac{\partial}{\partial y} \int_{-h}^{\eta} v d z=0 \\
\frac{\partial u}{\partial t}+u \frac{\partial u}{\partial x}+v \frac{\partial u}{\partial y}+w \frac{\partial u}{\partial z}-f v=\frac{1}{\rho_{0}} \frac{\partial P}{\partial x}+\frac{\partial}{\partial x}\left(\mu \frac{\partial u}{\partial x}\right)+\frac{\partial}{\partial y}\left(\mu \frac{\partial u}{\partial y}\right)+\frac{\partial}{\partial z}\left(v \frac{\partial u}{\partial z}\right) \\
\frac{\partial v}{\partial t}+u \frac{\partial v}{\partial x}+v \frac{\partial v}{\partial y}+w \frac{\partial v}{\partial z}-f u=\frac{1}{\rho_{0}} \frac{\partial P}{\partial y}+\frac{\partial}{\partial x}\left(\mu \frac{\partial v}{\partial x}\right)+\frac{\partial}{\partial y}\left(\mu \frac{\partial v}{\partial y}\right)+\frac{\partial}{\partial z}\left(v \frac{\partial v}{\partial z}\right) \\
\frac{\partial P}{\partial z}=-\rho g
\end{gathered}
$$


where $\eta(x, y, t)$ is the free-surface elevation; $h(x, y)$ is the bathymetric depth; $\mathrm{u}(x, y, z, t)$ is the horizontal velocity, with Cartesian components $(u, v) ; w$ is the vertical velocity; $f$ is the Coriolis factor; $\rho$ is the water density; reference value; $\rho_{0}$ is the reference density, which is set as $1025 \mathrm{~kg} \cdot \mathrm{m}^{-3}$; $P(x, y, t)$ is the pressure; $v$ is the vertical eddy viscosity; and $\mu$ is the horizontal eddy viscosity.

The vertical eddy viscosity was calculated by MY-2.5 [14], and the horizontal eddy viscosity was computed using Smagorinsky's formula [15] in the model.

The bottom drag coefficient is the most important parameter for validating water level in the model, which was determined by matching a logarithmic bottom layer to the model at a height $z$ above the bottom:

$$
C_{D B}=\max \left(\frac{\kappa^{2}}{\ln \left(z / z_{0}\right)}, 0.0025\right)
$$

where $\kappa=0.4$ is the von Karman constant and $z_{0}$ is the bottom roughness, which is typically of the order of $0.01 \mathrm{~m}[16]$.

FVCOM uses the point treatment technique to simulate wetting and drying processes based on the criterion as follows, for any given node

$$
\left\{\begin{array}{l}
\text { wet, if } D=h+\eta>D_{\min } \\
\text { dry, if } D=h+\eta \leq D_{\min }
\end{array}\right.
$$

and for any given triangular element

$$
\left\{\begin{array}{l}
\text { wet, if } D=\min \left(h_{N 1}, h_{N 2}, h_{N 3}\right)+\max \left(\eta_{N 1}, \eta_{N 2}, \eta_{N 3}\right)>D_{\min } \\
d r y, \text { if } D=\min \left(h_{N 1}, h_{N 2}, h_{N 3}\right)+\max \left(\eta_{N 1}, \eta_{N 2}, \eta_{N 3}\right) \leq D_{\min }
\end{array}\right.
$$

where subscripts $N 1, N 2$, and $N 3$ are the node numbers of a triangular element and $D_{\min }$ is the minimum depth $(=0.05 \mathrm{~m})$ for determining nodes or elements attributed to wet or dry.

\subsection{Estimation of Economic Loss}

With/without analysis is a common method used to evaluate project benefit [17]; it estimates the average annual flood losses (AAFL) with and without the project. Although there still exist some uncertainties in AAFL, it is an effectual approach [18]. Based on a similar concept to that of the AAFL, we used the average annual expected benefit (AAEB) to represent the yearly benefit after construction of the YFDT. The AAEB can be calculated according to a discontinued approach (AAEB $\mathrm{Ais}_{\text {is }}$ ) or a continued approach $\left(\mathrm{AAEB}_{\mathrm{con}}\right)$ as follows:

$$
\begin{gathered}
A A E B_{\text {dis }}=\sum_{i=1}^{N} P i_{i} \times E B_{i} \\
A A E B_{\text {con }}=\int f_{E B} d x
\end{gathered}
$$

where $P i_{i}$ is probability interval of an event; $E B_{i}$ is the expected benefit of an event; and $f_{E B}$ is an regression equation of expected benefits (EB) vs. probability of an event (Pr). 


\subsection{Model Implementation}

An accurate representation of the bottom topography by the model grid is the most important and fundamental requirement for a successful modeling study. The model grid must accurately represent the characteristics of the model domain of the Yuansantze flood diversion, the Keelung River, and the surrounding land.

Figure 2 a shows the bathymetry and topography of the model domain. The definition of study area depends on the availability of high-resolution digital elevation model (DEM) and accurate river cross-section data. Although large domain is proper for flooding simulation, this study focuses on high-resolution modeling on river stage and inundation extent at the specified district. The modeling domain defined in this study is enough to cover the maximum inundation extent. The model grid consists of 104,259 elements and 52,974 nodes in the horizontal direction (Figure 2b,c), and five uniform layers were specified in the vertical direction. An inflow boundary was specified at the upstream of the YFDT, and two outflow boundaries were set at the downstream of the YFDT and the Yuansantze diversion weir (Figure 2a). As the model was used to simulate the condition without the YFDT, the outflow open boundary at the Yuansantze diversion weir would be specified inactive to become a land boundary.

The whole model domain covers the Keelung River at the Ruifanf District and the surrounding land area on both sides of the Keeling River. An element resolution of approximately $10 \mathrm{~m}$ is established in the whole model domain. A digital elevation model (DEM) with a resolution of $5 \mathrm{~m} \times 5 \mathrm{~m}$ and measured cross-section data of the river channel were incorporated into the model grids to represent the topography of the levees. Since the information related to scale of bridge pier is limited, the bridges across the river are not considered in the model simulation. Once model meshes are generated, the Inverse Distance Weighting (IDW) method is adopted for interpolating the raw data to each model grid. A minimum depth of $0.05 \mathrm{~m}$ was used to delineate the wetting and drying processes. A $0.5 \mathrm{~s}$ time step was used in the simulations without any signs of numerical instability. Since the study area is far away from the Keelung River estuary (more than $50 \mathrm{~km}$ distance) and surrounded by hills, water level variations induce by wind stress can be neglected. Therefore storm surge and wind effects are not taken into account in the model simulation.

\subsection{Indices of Model Performance}

The performance of the three-dimensional hydrodynamic model was evaluated using three criteria: the mean absolute error (MAE), the root mean square error (RMSE), the coefficient of determination $\left(\mathrm{R}^{2}\right)$, and the optimal value of percent bias (PBIAS [19]). Positive values of PBIAS indicate overstimulation of model while negative values indicate underestimation of model [20]. The equations for these three criteria are as follows:

$$
\begin{gathered}
M A E=\frac{1}{N} \sum_{i=1}^{N}\left|\eta_{i}^{s}-\eta_{i}^{m}\right| \\
R M S E=\sqrt{\frac{1}{N} \sum_{i=1}^{N}\left(\eta_{i}^{s}-\eta_{i}^{m}\right)^{2}}
\end{gathered}
$$




$$
\begin{gathered}
R^{2}=1-\frac{\sum_{i=1}^{N}\left(\eta_{i}^{s}-\bar{\eta}^{m}\right)^{2}}{\sum_{i=1}^{N}\left(\eta_{i}^{m}-\bar{\eta}^{m}\right)^{2}}, \bar{\eta}^{m}=\frac{1}{N} \sum_{i=1}^{N} \eta_{i}^{m} \\
P B I A S=\frac{\sum_{i=1}^{n} \eta_{i}^{s}-\eta_{i}^{m}}{\sum_{i=1}^{n} \eta_{i}^{m}} \times 100
\end{gathered}
$$

where $N$ is the total number of data; $\eta_{i}^{s}$ is the predicted water level; and $\eta_{i}^{m}$ is measured water level.

\section{Model Validation}

We used several sets of observational data to determine the accuracy of the model in practice and to validate its predictive capabilities. Three typhoon events, including Typhoon Sinlaku (2008), Typhoon Megi (2010), and Typhoon Saola (2012), that brought heavy rain-fall and induced high flow in the Keelung River basin were adopted for validating water levels. One typhoon event, Typhoon Nari (2001), which resulted in severe inundation around the Keelung River, was used to validate the inundation extent.

Measured time-series river flows for every 10-minute period were imposed on the upstream of the YFDT (see Figure 2a) while two outflows at the downstream and the Yuansantze diversion weir were active. Table 1 illustrates the record of flood diversion at the Yuansantze diversion weir for three typhoon events. Figure 3 shows the model-data comparison of water levels at the Yuansantze diversion weir for Typhoon Sinlaku 2008 (Figure 3a), Typhoon Megi 2010 (Figure 3b), and Typhoon Saola 2012 (Figure 3c). Each figure includes the measured river flow at the upstream boundary in the upper panel, the water level in the middle panel, and the error between the simulated and observed water levels in the lower panel. Figure 3 also depicts that the river flow at the upstream boundary dominates the water level, which indicates that the errors are within $0.5 \mathrm{~m}$, even though the model slightly overestimates the measured water level for Typhoon Sinlaku event (Figure 3a). Figure $3 b$ also shows that the model slightly overestimates the measured water level when river flow decreases to $200 \mathrm{~m}^{3} / \mathrm{s}$. These errors may be the reason that some uncertainties are introduced by rating curve (i.e., stage-discharge relation) which is expected to be higher under low flow condition [21]. Overall, the model results are in good agreement with the observations. Table 2 shows the statistical errors for the difference between the simulated and observed water levels for the model validation. The average MAE, RMSE, and $\mathrm{R}^{2}$ values of three typhoon events are $0.117 \mathrm{~m}, 0.157 \mathrm{~m}$, and 0.93 at the Yuansantze diversion weir, respectively.

Table 1. Record of flood diversion for three typhoon events.

\begin{tabular}{ccc}
\hline Typhoon Event & $\begin{array}{c}\text { Maximum Diversion Discharge } \\
\text { from the Keelung River }\left(\mathbf{m}^{\mathbf{3}} / \mathbf{s}\right)\end{array}$ & $\begin{array}{c}\text { Total Diversion Water Volume } \\
\text { from the Keelung River }\left(\mathbf{m}^{\mathbf{3}}\right)\end{array}$ \\
\hline Typhoon Sinlaku (2008) & 247 & $1065 \times 10^{3}$ \\
Typhoon Megi (2010) & 455 & $1792 \times 10^{3}$ \\
Typhoon Saola (2012) & 773 & $1879 \times 10^{3}$ \\
\hline
\end{tabular}



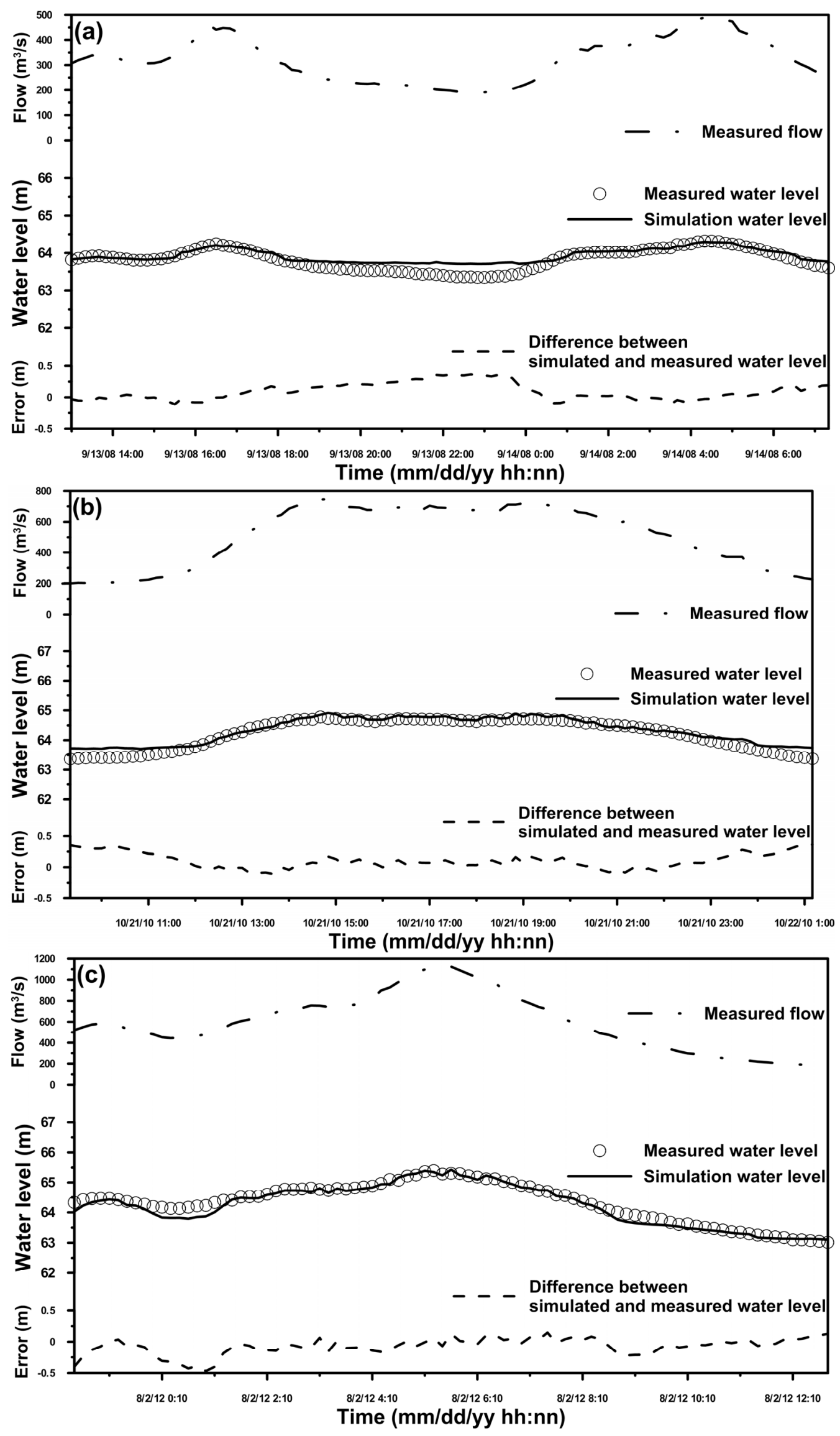

Figure 3. Model-data comparison of the water level at the Yuansantze diversion weir for (a) Typhoon Sinlaku (2008); (b) Typhoon Megi (2010); and (c) Typhoon Saola (2012). 
Table 2. Model performance for predicting water levels using two-dimensional and three-dimensional models at the Yuansnatze diversion weir for different typhoon events.

\begin{tabular}{cccccc}
\hline Typhoon Event & Model & MAE (m) & RMSE (m) & $\mathbf{R}^{\mathbf{2}}$ & PBIAS (\%) \\
\hline \multirow{2}{*}{ Typhoon Sinlaku (2008) } & Two-dimensional model & 0.19 & 0.20 & 0.86 & 0.29 \\
& Three-dimensional model & 0.12 & 0.16 & 0.87 & 0.15 \\
\hline \multirow{2}{*}{ Typhoon Megi (2010) } & Two-dimensional model & 0.23 & 0.24 & 0.95 & 0.35 \\
& Three-dimensional model & 0.12 & 0.16 & 0.96 & 0.16 \\
\hline \multirow{2}{*}{ Typhoon Saola (2012) } & Two-dimensional model & 0.34 & 0.36 & 0.96 & 0.52 \\
& Three-dimensional model & 0.11 & 0.15 & 0.96 & -0.11 \\
\hline
\end{tabular}

In order to compare the performance between two-dimensional model and three-dimensional model, the two-dimensional version of FVCOM model (FVCOM-2D) was used to simulate water levels for three typhoon events. FVCOM-2D model solves vertically-integrated momentum and continuity equations to obtain the free-surface elevation and depth-averaged horizontal velocity. The details can be found in Chen et al. [12]. Recently, FVCOM-2D model was applied to deal with tsunami propagation and inundation problems [22]. The two-dimensional model overestimated the observed water levels, comparing to the simulated results with three-dimensional model (Figure 4). Table 2 indicates that the performance with three-dimensional model is better than that with two-dimensional model. The average MAE, RMSE, and $\mathrm{R}^{2}$ values of three typhoon events are $0.253 \mathrm{~m}, 0.267 \mathrm{~m}$, and 0.92 at the Yuansantze diversion weir, respectively, when the two-dimensional model is used to predict water levels.
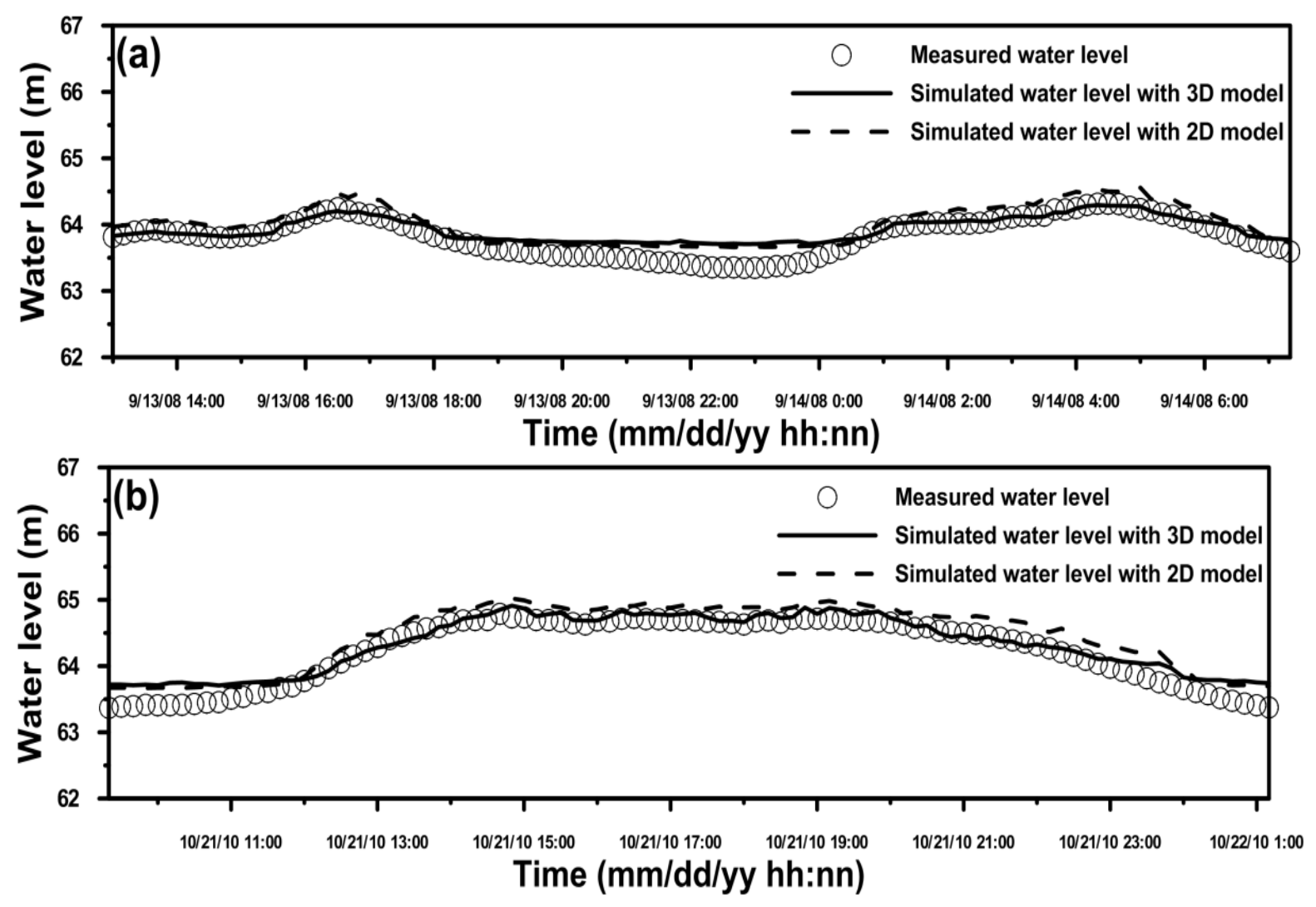

Figure 4. Cont. 


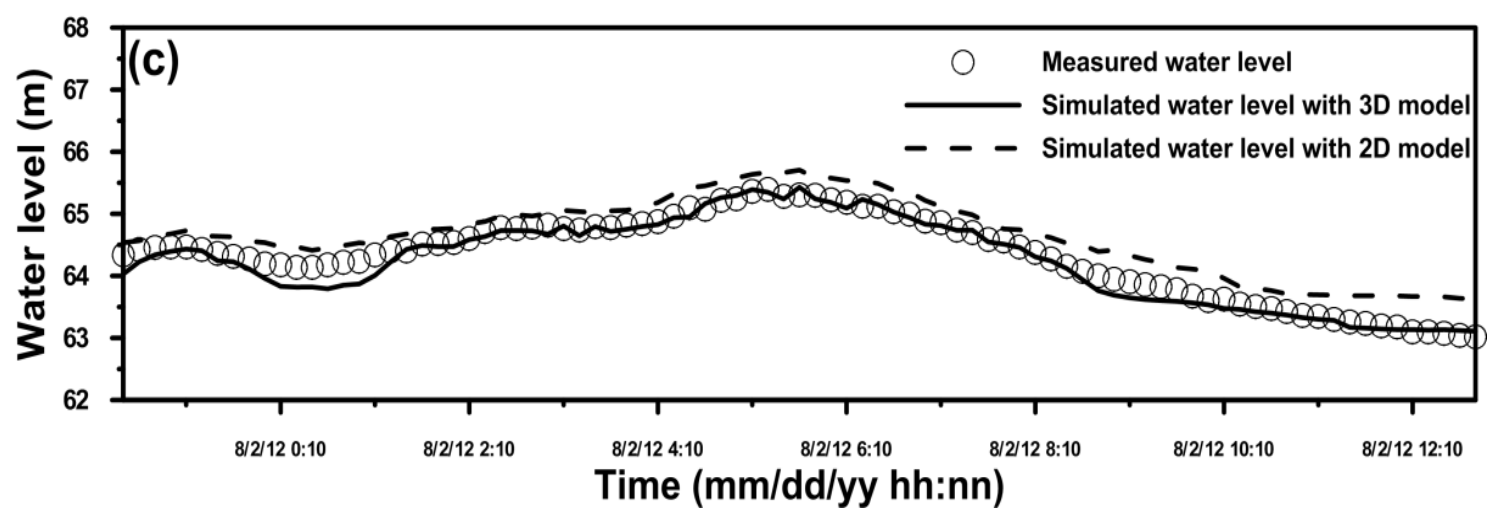

Figure 4. Comparison of performance for predicting water levels using two-dimensional and three-dimensional hydrodynamic models for (a) Typhoon Sinlaku (2008); (b) Typhoon Megi (2010); and (c) Typhoon Saola (2012).

The comparison of the simulated and surveyed inundation extent for Typhoon Nari (2001) is presented in Figure 5. The results reveal that the model underestimates the inundation area which is $20.1 \%$. There are two main reasons to cause the discrepancy of the inundation area. The first reason is the precipitation excluded in the model simulation and the second reason is the topographic and bathymetric issues. The available DEM was measured in 2006 and river cross-section data was measured in 2012. These measured data were used to generate the meshes for model simulation. The topographic and bathymetric data measured in 2006 and 2012 are difficult to really reflect the terrain because the Typhoon Nari was occurred in 2001.

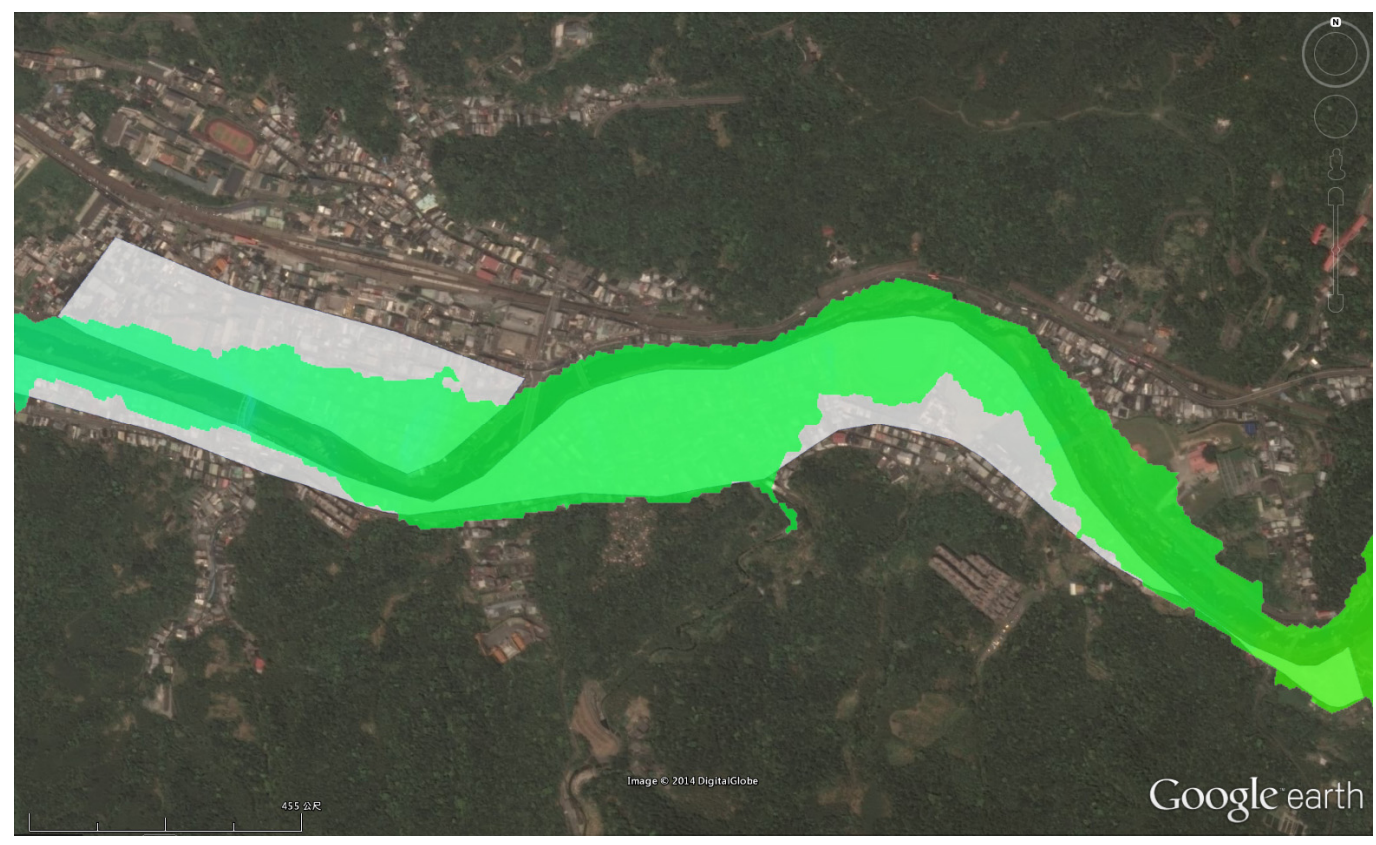

Figure 5. Model (green color)-data (white color) comparison of the inundation extent during Typhoon Nari (2001).

Through the model validation procedure, the bottom roughness heights $\left(z_{0}\right)$ are set to be $0.05 \mathrm{~m}$ and $0.06 \mathrm{~m}$ for river and land, respectively. It means that the roughness distribution is not uniform for the whole domain. 
To understand the influence of bottom roughness height on the inundation extent, two sensitivity runs were conducted with increase $50 \%$ (i.e., $0.075 \mathrm{~m}$ for river and $0.09 \mathrm{~m}$ for land) and decrease $50 \%$ (i.e., $0.025 \mathrm{~m}$ for river and $0.03 \mathrm{~m}$ for land) on bottom roughness heights. The results reveal that the model underestimates the inundation area which is $18.9 \%$ as the bottom roughness heights increase $50 \%$. When the bottom roughness heights decrease $50 \%$, the model underestimates the inundation area reaching $21 \%$. We found that the bottom roughness was not very sensitive to inundation area. Ghimire [23] applied a two-dimensional hydrodynamic model-TUFLOW to assess the flood risk from extreme storm events. He also found that the roughness parameter was not very sensitive in terms of the inundated area. Similarly, sensitivity test for the roughness of the agricultural land which was the dominant land use within the floodplain, indicated that the model sensitivity to the change in floodplain roughness was not very significant.

\section{Model Application and Discussion}

The validated model was then used to assess the influence of the YFDT on mitigating the river level and inundation extent and on reducing the inundation-induced economic loss.

\subsection{Influence of the YFDT on River Level and Inundation Extent}

To demonstrate the capability of the YDFT to mitigate the river level and inundation extent, different return periods were conducted. The peak flows for the 2-year, 5-year, 10-year, 20-year, 50-year, 100-year, and 200-year return periods are 524, 837, 1022, 1186, 1375, 1502, and $1620 \mathrm{~m}^{3} / \mathrm{s}$ [24], which are used to specify the inflows at the upstream open boundary (see Figure 2a). Figure 6 shows only the time-series river flows at the upstream open boundary for the 50-year, 100-year, and 200-year return periods.

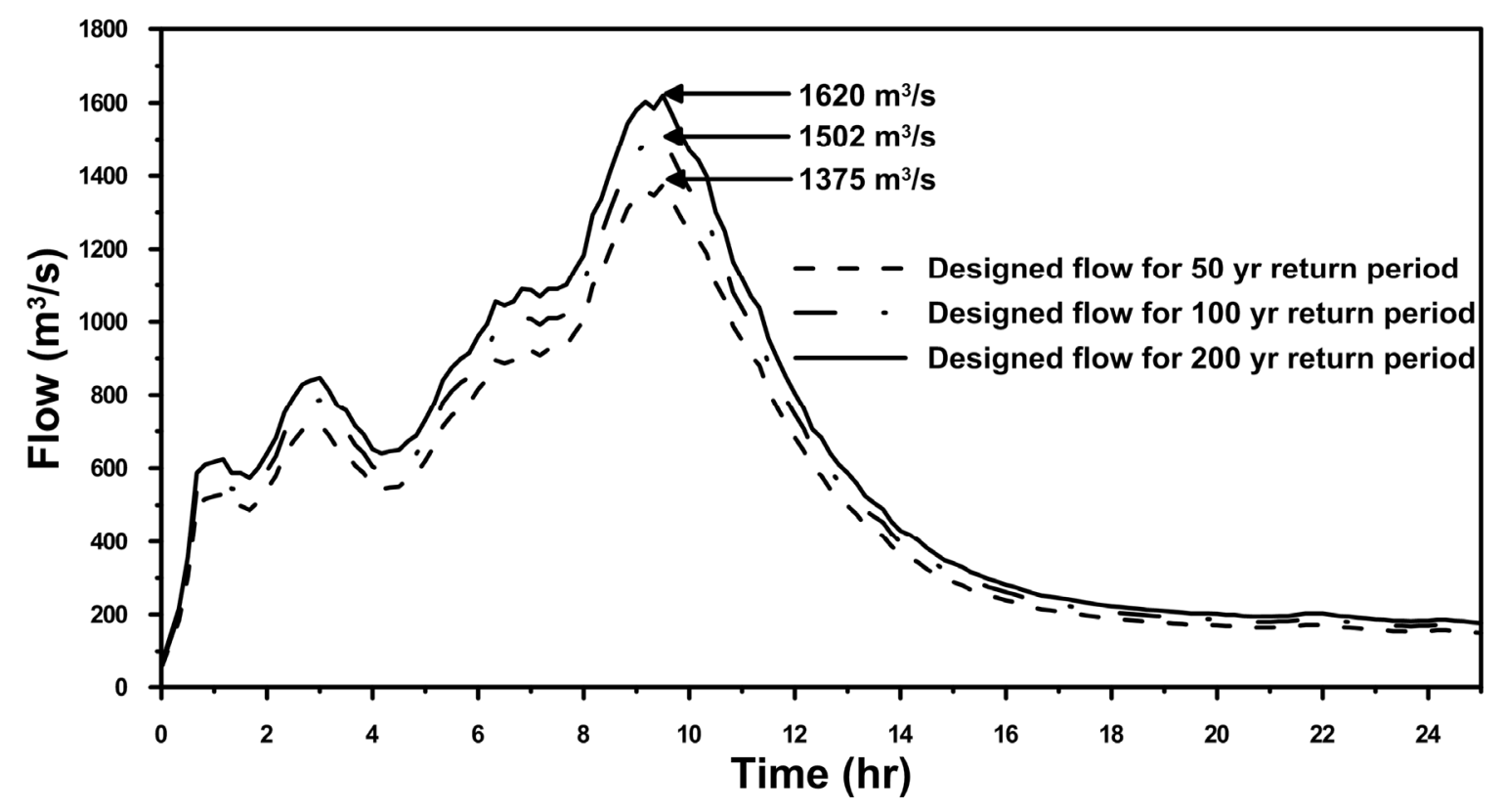

Figure 6. Designed river flow at the upstream boundary for the 50-year, 100-year, and 200-year return periods. 
The model was conducted with and without YDFT conditions to determine the efficiency of the YDFT. Figure 7 presents river levels along the Keelung River from the Jieshou Bridge to the upstream with and without the YDFT under different return periods. It shows that the water levels with the YDFT significantly decrease to approximately $3 \mathrm{~m}$ at the downstream reaches compared to those without the YDFT. It can be observed that the difference in water levels with and without the YDFT reaches $4 \mathrm{~m}$ to $5 \mathrm{~m}$ at the distance from the Jieshou Bridge to above $2000 \mathrm{~m}$ because the steep riverbed causes an increase in the difference in water levels. Figure 8 shows the comparison of the time-series water levels at the Ruifang Bridge (see Figure 1) with and without the YDFT under different return periods. It shows that the water levels significantly decrease with the YDFT.
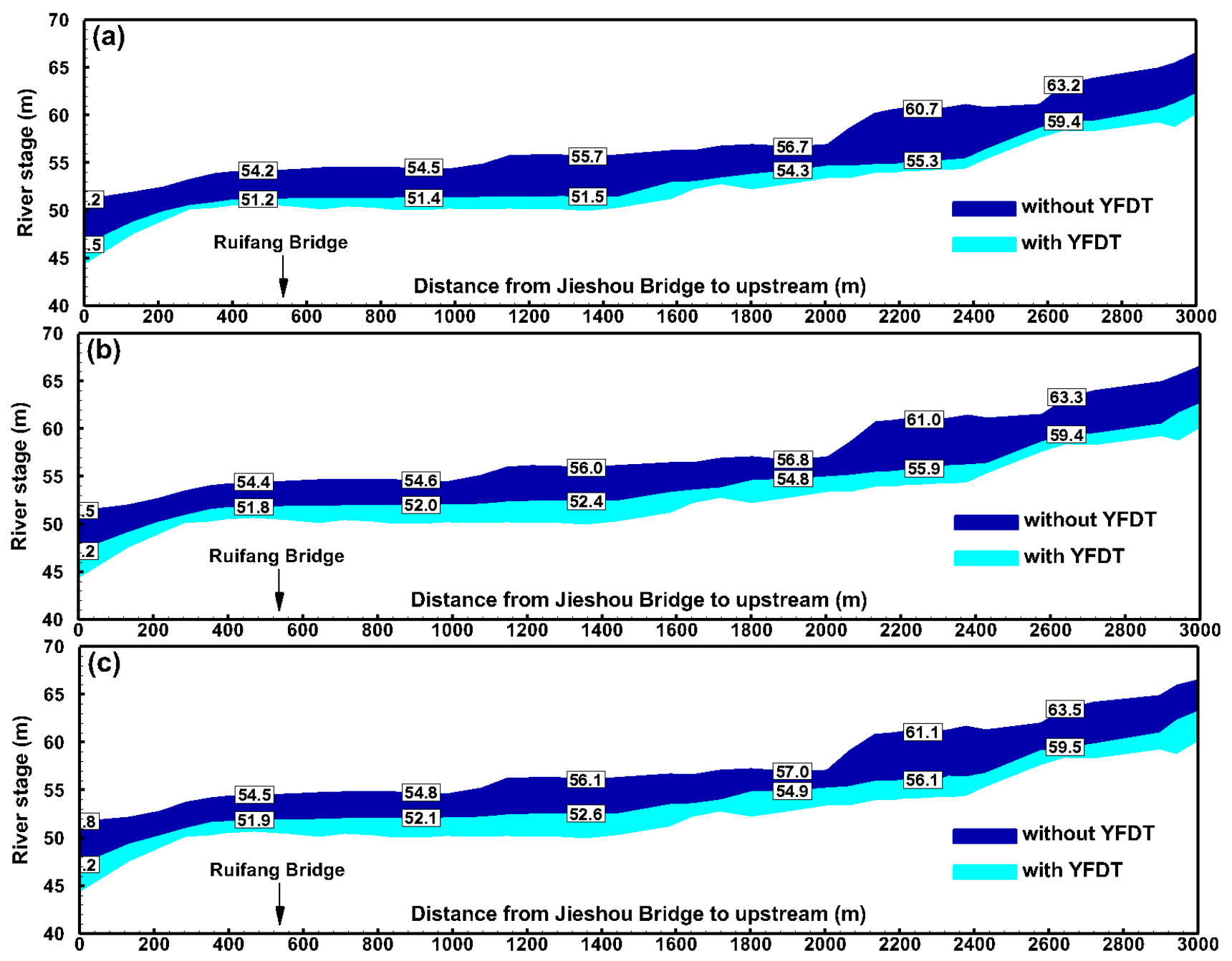

Figure 7. Comparison of the water levels along the Keelung River with (cyan color) and without (blue color) the Yuansantze flood diversion tunnel (YFDT) for the following return periods: (a) 50-year; (b) 100-year; and (c) 200-year. 

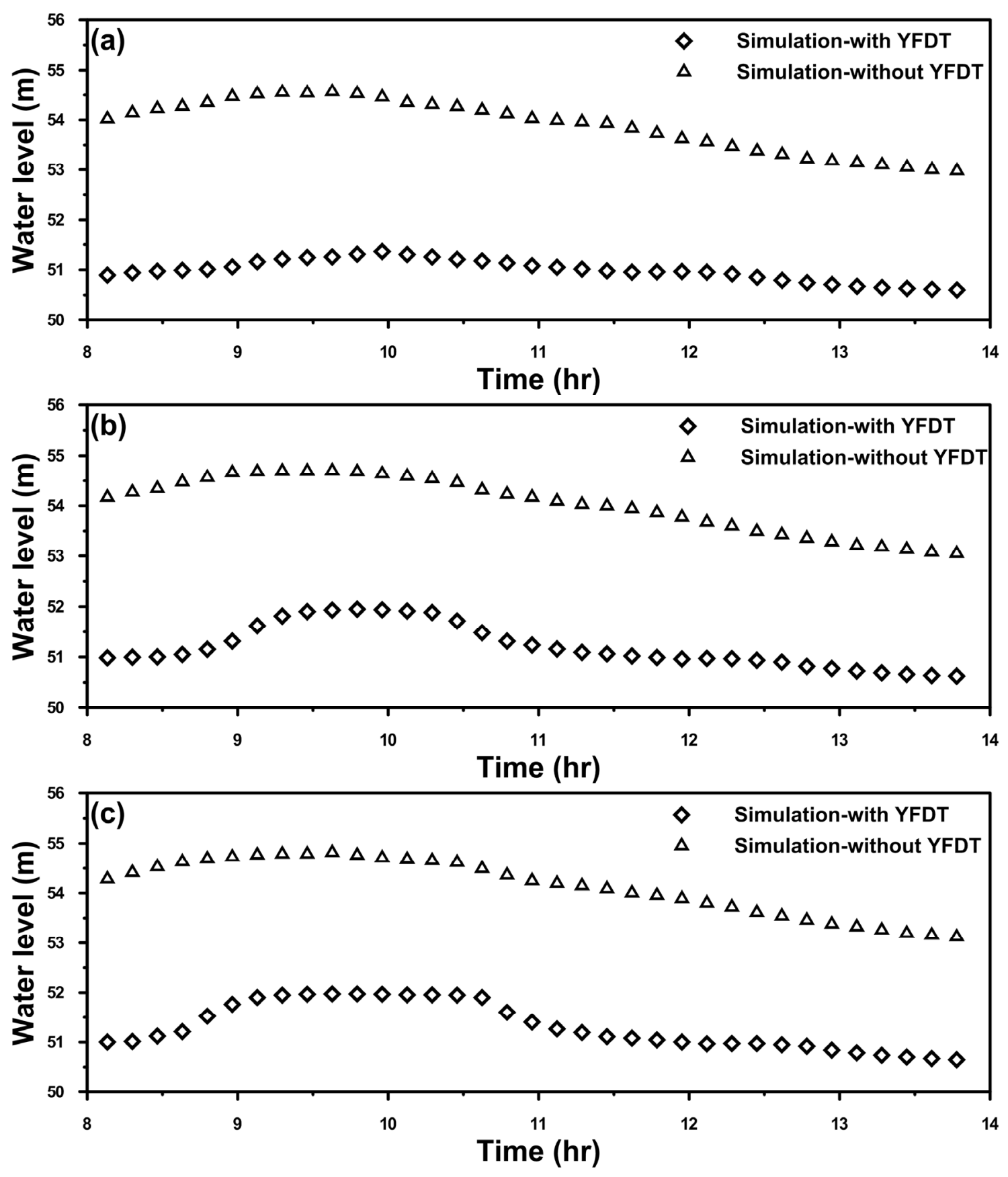

Figure 8. Comparison of time-series water levels at the Ruifang Bridge with and without the Yuansantze flood diversion tunnel (YFDT) for the following return periods: (a) 50-year; (b) 100-year; and (c) 200-year.

The inundation areas under the 50-year, 100-year, and 200-year return periods with and without the YDFT are presented in Figure 9. The inundation extents are significantly reduced when the YDFT is active. Figure 9 also shows that the decrease in inundation depth exceeds $3 \mathrm{~m}$ and the decrease in inundation extent is more than $50 \%$ at the Ruifang District with the YFDT. The inundations were induced by overtopping at the upstream of Keelung River without YFDT. Table 3 presents the maximum inundation area and inundation depth for different return periods with and without YFDT. For the 2-year and 5-year return periods, no inundation occurs with the YFDT. Over a 10-year return period, the inundation area and depth significantly decrease with the YFDT compared to those without the YFDT. 


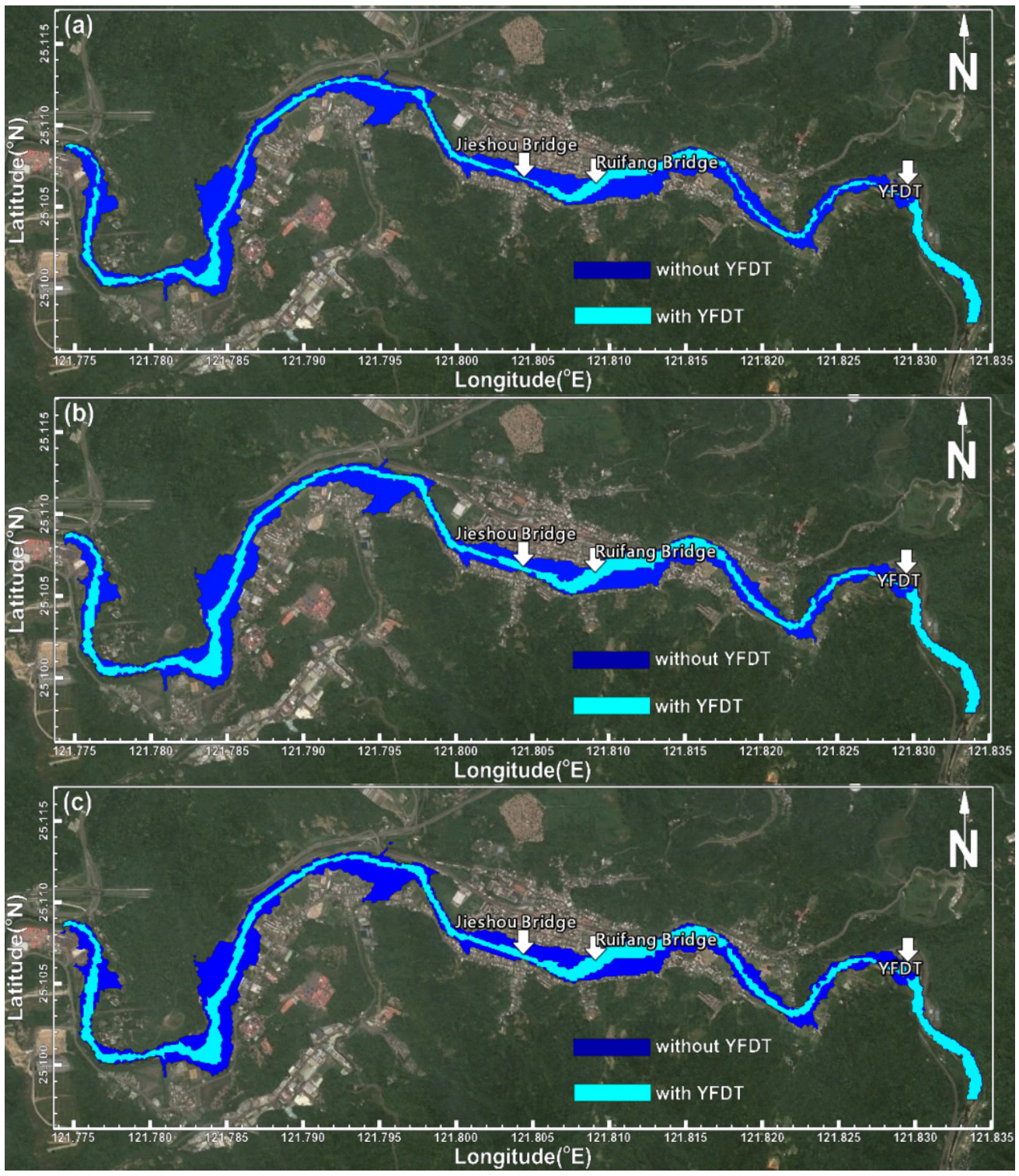

Figure 9. Comparison of the maximum inundation extent with (cyan color) and without (blue color) the Yuansantze flood diversion tunnel (YFDT) for the following return period: (a) 50-year; (b) 100-year; and (c) 200-year.

Table 3. Maximum inundation area and inundation depth for different return periods with and without YFDT conditions.

\begin{tabular}{ccccccc}
\hline \multirow{2}{*}{ Return Period } & \multicolumn{2}{c}{ With YFDT } & & \multicolumn{2}{c}{ Without YFDT } \\
\cline { 2 - 3 } \cline { 5 - 6 } & $\begin{array}{c}\text { Inundation } \\
\left.\text { Area } \mathbf{( k m}^{2}\right)\end{array}$ & $\begin{array}{c}\text { Inundation } \\
\text { Depth } \mathbf{( m )}\end{array}$ & & $\begin{array}{c}\text { Inundation } \\
\left.\text { Area } \mathbf{( k m}^{\mathbf{2}}\right)\end{array}$ & $\begin{array}{c}\text { Inundation } \\
\text { Depth (m) }\end{array}$ \\
\hline 2-year & -- & -- & & 0.71 & 3.16 \\
5-year & -- & -- & & 0.87 & 3.84 \\
10-year & 0.28 & 0.56 & & 0.99 & 4.15 \\
20-year & 0.29 & 0.57 & & 1.05 & 4.33 \\
50-year & 0.39 & 1.23 & & 1.13 & 4.52 \\
100-year & 0.50 & 1.89 & & 1.20 & 4.63 \\
200-year & 0.52 & 1.96 & & 1.23 & 4.82 \\
\hline
\end{tabular}

Note: Sign '--' represents no inundation occurred. 


\subsection{Influence of the YFDT on Economic Loss}

The National Science and Technology Center for Disaster Reduction (NCDR) developed a loss assessment system for flood disaster, called the Taiwan Typhoon Loss Assessment System (TLAS) [25]. The total economic losses are estimated using the effected population module, loss in residential module, loss in industry and commercial module, loss in agriculture module, loss in hydraulic and traffic module, lost in infrastructure module, and other (such as bare land, land not-in-use) modules. Each module has its corresponding land use. The classification of land use in the model domain is shown in Figure 10. TLAS has been verified for its accuracy in evaluating the economic losses with the actual typhoon events in Taiwan. The details of the system verification can be found in Li et al. [25].

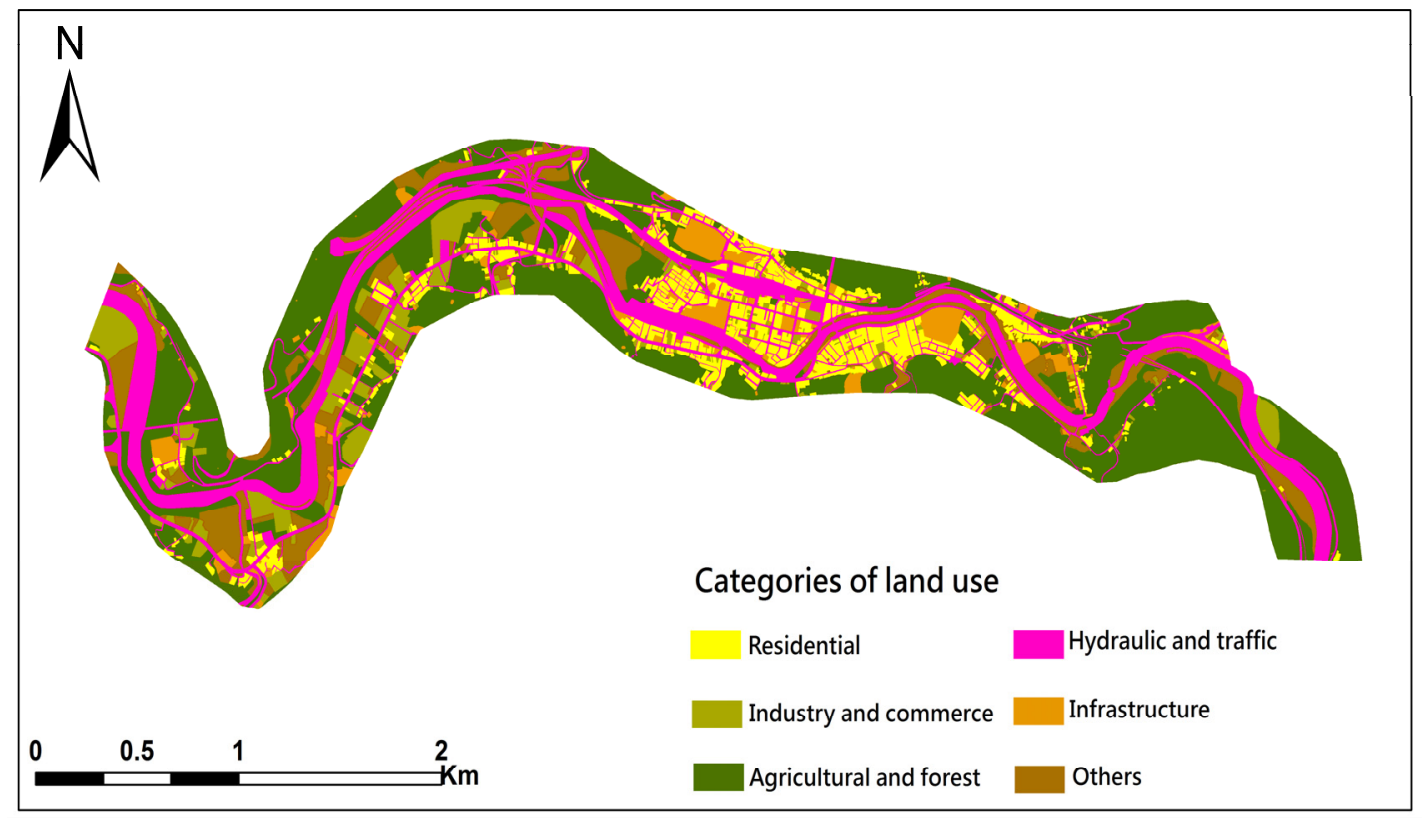

Figure 10. Land use in the model domain.

Table 4 lists the total economic losses based on the calculation using TLAS with and without the YFDT for the 2-year, 5-year, 10-year, 20-year, 50-year, 100-year, and 200-year return periods. AAEB dis $_{\text {si }}$ is a summation of column (e) in Table 4. Figure 11 plots the distribution of expected benefit (EB) vs. the probability of an event $(\mathrm{Pr})$. The regression equation for $\mathrm{EB}$ and $\operatorname{Pr}$ is $f_{E B}=536.955 \cdot e^{-1.599 \mathrm{Pr}}$, and the $\mathrm{R}^{2}$ value is 0.986 . $A A E B$ con is the area below the curve of $f_{E B}$ shown in Figure 11. It can be obtained through integrating equation $f_{E B}$. $\mathrm{AAEB}_{\text {dis }}$ and $\mathrm{AAEB}_{\text {con }}$ were 183.96 million NTD and 184.86 million NTD, respectively, as computed using Equations (9) and (10). The difference between these two approaches is only $0.49 \%$. Hence, we conclude that the yearly benefit after the construction of the YFDT is approximately 184 million NTD in the Ruifang District. One should note that to avoid overestimating the average annual expected benefit (AAEB) with the YFDT, the average annual flood losses for events with a probability higher than 0.5 (i.e., 2-year return period) are neglected. In other words, a conservative estimation is adopted in the current study. 
Table 4. Estimation of economic loss and benefit for different return periods with and without YFDT conditions.

\begin{tabular}{|c|c|c|c|c|c|}
\hline \multirow[b]{2}{*}{ Return Period } & \multirow[b]{2}{*}{$\operatorname{Pr}(\mathbf{a})$} & \multicolumn{2}{|c|}{ Economic Loss (NTD, in Millions) } & \multirow[b]{2}{*}{$\mathbf{P i}(\mathrm{d})$} & \multirow{2}{*}{$\begin{array}{c}\text { Expected Benefits (EB) } \\
(\mathrm{NTD}, \text { in Millions) } \\
(\mathrm{e})=(\mathrm{c}-\mathrm{b}) \times \mathbf{d} \\
\end{array}$} \\
\hline & & With YFDT (b) & Without YFDT (c) & & \\
\hline 2-year & 0.5 & - & 246 & 0.150 & 36.90 \\
\hline 5-year & 0.2 & - & 379 & 0.200 & 75.80 \\
\hline 10-year & 0.1 & 13 & 456 & 0.075 & 33.23 \\
\hline 20-year & 0.05 & 14 & 502 & 0.040 & 19.52 \\
\hline 50-year & 0.02 & 45 & 558 & 0.020 & 10.26 \\
\hline 100-year & 0.01 & 90 & 622 & 0.0075 & 3.99 \\
\hline 200-year & 0.005 & 98 & 666 & 0.0075 & 4.26 \\
\hline \multicolumn{5}{|c|}{ 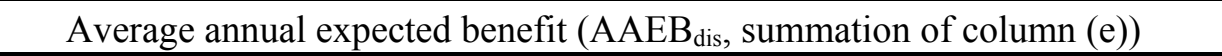 } & 183.61 \\
\hline
\end{tabular}

Notes: Sign '--' represents no economic losses occurred; Pr is the probability of an event; and Pi is the probability interval.

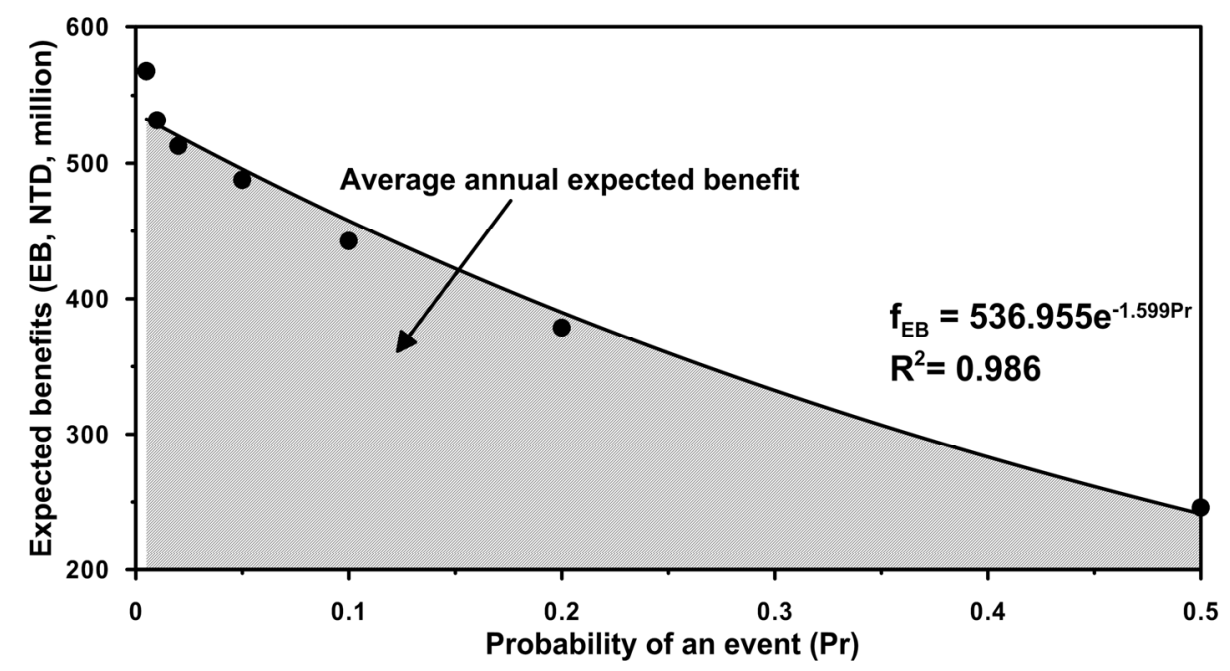

Figure 11. Expected benefit vs. probability of an event for different return periods.

\subsection{Discussion}

In northern Taiwan, YFDT is an important construction that costs 6 billion NTD. Based on the modeling results, the YFDT project significantly reduced the water level, inundation extent, and economic loss. After the TFDT was constructed, the inundation has not been occurred around the Keelung River during typhoon events. It means that the YFDT has elaborated maximum function to mitigate flooding disaster. Because the TFDT diverts water from the upper Keelung River basin into the East China Sea, one concern is that the pollution would be discharged into coastal sea. Cerco et al. [26] examined the impact of flood-diversion tunnel on Newark Bay and adjacent waters using the CH3D hydrodynamic model and the CE-QUAL-ICM water quality model. Quantities computed included tides, currents, salinity, temperature, dissolved oxygen (DO), and biochemical oxygen demand. They concluded that the impact of the tunnel on DO and temperature was short-lived and of limited spatial extent. Impact of the tunnel on salinity was indiscernible. 
The influence of the flood-diversion on the East China Sea and adjacent waters has not yet been investigated and assessed. In future study, a three-dimensional hydrodynamic and water quality model would be used to provide the information required to evaluate the effect of YFDT on water quality and ecosystem in the vicinity of the outlet.

\section{Conclusions}

This study successfully applied a three-dimensional, unstructured grid, finite-volume model at the upstream of the Keelung River to investigate the influence of a flood diversion project on mitigating river stage, inundation extent, and economic loss. The model was validated with available water level and inundation extent data. The simulated results showed good agreement with field measurements of water level with three typhoon events but underestimated the inundation area with Typhoon Nari (2001).

The designed river flows with different return periods in the Yuansantze basin were adopted to simulate river stages and inundation area with and without the YFDT using the validated model. The results demonstrated that the decrease in the river stage is approximately $3 \mathrm{~m}$ and that the reduction in the inundation extent is more than $50 \%$ in the Ruifang District with the YFDT. Additionally, the flood-related economic losses were evaluated using the Taiwan Typhoon Loss Assessment System (TLAS). The evaluation reveals that the YFDT significantly reduces the economic losses due to the decreases in inundation extent and inundation depth. The average annual expected benefit after construction of the YFDT in the Ruifang District is approximately 184 million NTD. Our study also indicates that the combination of a hydrodynamic model and an economic loss assessment system is a powerful tool for assessing project benefits.

Although the three-dimensional model provides accurate simulations, there are still some limitations and disadvantages. For instances, high-resolution digit elevation model (DEM) and accurate river cross-section and river flow data are necessary for accurate hydrodynamic modeling. Besides, high-performance computers are indispensable for the high-resolution three-dimensional modeling. The effect of precipitation on inundation simulation will be considered in the model for accurate prediction of inundation in the future study.

\section{Acknowledgments}

This project was funded by the Ministry of Science and Technology (MOST), Taiwan, grant No. 103-2625-M-239-001. The authors would like to thank the Taiwan Water Resources Agency for providing the observational data. The authors sincerely thank two anonymous reviewers for their valuable comments to substantially improve this paper.

\section{Author Contributions}

Wen-Cheng Liu supervised the progress of the Ministry of Science and Technology project and constructed this paper. Co-author Wei-Bo Chen, Huei-Shuin Fu, and Jiun-Huei Jang executed the model simulations and discussed the results with Wen-Cheng Liu. 


\section{Conflicts of Interest}

The authors declare no conflict of interest.

\section{References}

1. Valdiya, K.S. Coping with Natural Hazards: Indian Context; Orient BlackSwan: Andhra Pradesh, India, 2004; p. 284.

2. Liu, W.C.; Wu, C.Y. Flash flood routing modeling for levee-breaks and overbank flows due to typhoon events in a complicated river system. Nat. Hazards 2011, 58, 2057-1076.

3. Hsieh, L.S.; Hsu, M.H.; Li, M.H. An assessment of structural measures for flood-prone lowlands with high population density along the Keelung River in Taiwan. Nat. Hazards 2006, 37, 133-152.

4. The 10th River Management Office. Hydrological Measurements and Hydraulic Analyses for the Yuanshantz Flood Diversion Works; Technical Report; Water Resources Agency: Taipei, Taiwan, 2013. (In Chinese)

5. Yang, Z.; Wang, T.; Khangaonkar, T.; Breithaupt, S. Integrated modeling of flood flows and tidal hydrodynamics over a coastal floodplain. Environ. Fluid Mech. 2012, 12, 63-80.

6. Condon, A.J.; Sheng, Y.P. Evaluation of coastal inundation hazard for present and future climates. Nat. Hazards 2012, 62, 345-373.

7. Allison, M.A.; Vosburg, B.M.; Ramirez, M.T.; Meselhe, E.A. Mississippi River channel response to the Bonnet Carre Spillway opening in the 2011 flood and it implications for the design and operation of river diversions. J. Hydrol. 2013, 477, 104-118.

8. Chen, C.N.; Tsai, C.H.; Wu, M.H.; Tsai, C.T. Numerical simulation of potential inundation in a coastal zone. J. Flood Risk Manag. 2015, in press.

9. Chen, W.B.; Liu, W.C. Modeling flood inundation induced by river flow and storm surges over a river basin. Water 2014, 6, 3182-3199.

10. Merwade, V.; Cook, A.; Coonrod, J. GIS techniques for creating river terrain models for hydrodynamic modeling and flood inundation mapping. Environ. Model. Softw. 2008, 23, 1300-1311.

11. Water Resource Planning Institute. Physical Model Studies for Detailed Design of the Yuanshantz Flood Diversion Works; Technical Report; Water Resources Agency: Taichung, Taiwan, 2005. (In Chinese)

12. Chen, C.; Liu, H.; Beardsley, R.C. An unstructured grid, finite-volume, three-dimensional, primitive equations ocean model: Application to coastal ocean and estuaries. J. Atmos. Ocean. Technol. 2003, 20, 159-186.

13. Chen, C.; Beardsley, R.; Cowles, G. An unstructured grid, finite-volume coastal ocean model (FVCOM) system. Oceanography 2006, 19, 78-89.

14. Mellor, G.L.; Yamada, T. Development of a turbulence closure model for geophysical fluid problems. Rev. Geophys. Space Phys. 1982, 20, 851-875.

15. Smagorinsky, J. General circulation experiments with the primitive equations. Part I. The basic experiment. Mon. Weather Rev. 1963, 91, 99-164. 
16. Blumberg, A.F.; Mellor, G.L. A description of a three-dimensional coastal ocean circulation model. In Three-Dimensional Coastal Ocean Models; Heaps, N., Ed.; American Geophysical Union: Washington, DC, USA, 1987; Volume 4, pp. 1-16.

17. Helweg, O.J. Water Resources Planning and Management; John Wiley \& Sons: Hoboken, NJ, USA, 1985.

18. Arnell, N.W. Expected annual damages and uncertainties in flood frequency estimation. J. Water Resour. Plan. Manag. 1989, 115, 94-107.

19. Gupta, H.V.; Sorooshian, S.; Yapo, P.O. Status of automatic calibration for hydrologic models: Comparison with multilevel expert calibration. J. Hydrol. Eng. 1999, 4, 135-143.

20. Moriasi, D.N.; Arnold, J.G.; Van Liew, M.W.; Bingner, R.L.; Harmel, R.D.; Veith, T.L. Model evaluation guidelines for systematic quantification of accuracy in watershed simulations. Am. Soc. Agric. Biol. Eng. 2007, 50, 885-900.

21. Domeneghetti, A.; Castellarin, A.; Brath, A. Assessing rating-curve uncertainty and its effects on hydraulic calibration. Hydrol. Earth Syst. Sci. 2012, 16, 1191-1202.

22. Sasaki, J.; Komatsu, Y.; Matsumaru, R.; Wiyono, R.U.A. Unstructured model investigation of 2004 Indian Ocean tsunami inundation in Banda Aceh, Indonesia. J. Coast. Res. 2011, 64, 941-945.

23. Ghimire, S. Application of a $2 \mathrm{D}$ hydrodynamic model for assessing flood risk from extreme storm events. Climate 2013, 1, 148-162.

24. Water Resource Agency (WRA). Hydrology Measurements and Hydraulic Analyses for Inflow Region of the Yuanshantze Flood Diversion (1/3); Technical Report; WRA: Taipei, Taiwan, 2009. (In Chinese)

25. Li, H.C.; Chen, Y.C.; Guo, M.J. The development and application of Taiwan loss assessment system (TALS). J. Taiwan Agric. Eng. 2013, 59, 42-55. (In Chinese)

26. Cerco, C.F.; Bunch, B.; Letter, J. Impact of flood-diversion tunnel on Newark Bay and adjacent waters. J. Hydraul. Eng. 1999, 125, 328-338.

(C) 2015 by the authors; licensee MDPI, Basel, Switzerland. This article is an open access article distributed under the terms and conditions of the Creative Commons Attribution license (http://creativecommons.org/licenses/by/4.0/). 